\title{
Study of the impact on Salmonella of moving outdoor pigs to fresh land
}

\author{
R. P. SMITH ${ }^{1} *$ V. ANDRES ${ }^{2}$, L. DORMER ${ }^{1}$, R. GOSLING ${ }^{1}$, \\ C. OASTLER ${ }^{1}$ AND R. H. DAVIES ${ }^{1}$ \\ ${ }_{1}^{1}$ Animal and Plant Health Agency (APHA), Woodham Lane, New Haw, Addlestone, Surrey KT15 3NB, UK \\ ${ }^{2}$ APHA Field Services - South East, Suite 2 Gatwick House, Peeks Brook Lane, Horley, Surrey RH6 9ST, UK
}

Received 24 January 2017; Final revision 28 March 2017; Accepted 12 April 2017;

first published online 15 May 2017

\section{SUMMARY}

Anecdotal evidence has suggested that outdoor-kept pigs show an improvement to health and productivity after being moved to a new site. This study explores whether Salmonella occurrence reduced and was sustained after moving to a new site. Nine farms were followed for a year in which four sampling visits were completed. The highest detection of Salmonella was from pooled faecal dropping from pigs, run-off/ pooled water, rodents and wild birds. Descriptive summaries showed that the prevalence of both all Salmonella and serovars of public health importance were lower at all visits after the move. Some variability was shown in results from individual farms, but a year after the move, six farms still maintained a lower prevalence. A risk factor model showed that the prevalence at visits 2 and 3 after the move was significantly lower than baseline, after accounting for a number of significant factors that were included in the model. These were sample type and seasonality (included as $a$ priori), presence of coughing in the sampled group and Glasser's disease on the farm, and the use of tent or kennel accommodation. This finding provides important evidence that more frequent site moves may help reduce Salmonella prevalence in outdoor herds.

Key words: Outdoor, pig, Salmonella, site movement.

\section{INTRODUCTION}

Salmonellosis is consistently the second most commonly reported zoonosis in Europe and in the UK, with more than 80000 cases reported annually and an overall economic burden estimated to be close to three billion Euros per year [1]. Salmonella in pigs is an important source of human salmonellosis [2] and Great Britain was amongst the countries with the highest prevalence in pigs in the European Union (EU) in 2007, with Salmonella isolated from $21.7 \%$ of ileocaecal lymph node samples and $15 \cdot 2 \%$ of

\footnotetext{
* Author for correspondence: Dr R. P. Smith, APHA - Weybridge, New Haw, Addlestone, Surrey KT15 3NB, UK.

(Email: Richard.P.Smith@apha.gsi.gov.uk)
}

carcass swabs (compared with an average of $10 \cdot 3 \%$ and $8 \cdot 3 \%$ across the EU, respectively) $[3,4]$.

The use of outdoor pig production in Great Britain has been growing in popularity since the late 1990s and currently around $40 \%$ of commercially produced pigs are believed to be born outdoors. However, outdoor pigs are mainly breeding animals and their offspring, as only around $5 \%$ of pigs spend their entire life outdoors, with most finisher pigs being reared indoors [5, 6]. Outdoor pig production has a tendency for high Salmonella seroprevalence at slaughter [7, 8] and a high frequency of environmental Salmonella contamination [9], with evidence for a wide diversity of resident and transient infections with different serovars, often showing some overlap with local environmental and wildlife isolates [10]. 
Outdoor pigs may be at increased risk of infection due to: the lack of a controlled environment that can be cleaned and disinfected between batches of pigs; less control over exposure of pigs to factors such as cold and heat stress; and the increased exposure to Salmonella through difficulties in applying biosecurity for personnel and vehicles as well as increased contact with the environment and wildlife [10-12]. Outdoor farms are typically run as free-range (including organic) enterprises, with pigs bedded on earth floors with straw, which could increase the exposure to faeces in comparison to pigs on conventional farms, which can be kept on slatted floors that help separate contaminated faeces from the pigs' environment [13-15]. In a US study comparing the serological results from 616 samples from outdoor, antimicrobialfree farms and conventional indoor-reared farms, a significantly higher seroprevalence of Salmonella was detected in the outdoor herds than indoors, with $54 \%$ samples positive compared with $39 \%$, respectively [16]. Contrary to these findings, another study found no overall differences in the proportion of Salmonella seropositive animals comparing organic, outdoor and indoor pig farm production systems [17].

In general, most studies suggest that the inevitably less biosecure outdoor environment limits the level of infection control that can be achieved. This highlights that more research is needed to understand Salmonella incursion, persistence and control on a wider variety of farm types. New evidence is needed to help farmers select appropriate management options to provide protection against infection on their particular farm type. Anecdotal information has shown that moving outdoor pigs to new land is usually followed by an improvement in herd health and productivity. It is believed that outdoor herds in the UK typically move site every $2-3$ years. The aim of this longitudinal study was to investigate the effect on the occurrence of Salmonella of moving pigs to new land and the sustainability of any improvements over a 1-year period. Such data would help to determine whether more frequent movement to new land would help improve the control of Salmonella in outdoor pig production.

\section{METHOD}

\section{Farm selection}

A total of 119 farms were identified through the industry representative body (Agriculture and Horticulture
Table 1. Description of the nine outdoor pig farms participating in the study

\begin{tabular}{lll}
\hline \hline Farm ID & Farm type & Farm size category \\
\hline $1-\mathrm{O}$ & Breeder & $750-1000$ sows \\
$2-\mathrm{O}$ & Finisher & $>2500$ finishers \\
$3-\mathrm{O}$ & Finisher & $>2500$ finishers \\
$4-\mathrm{O}$ & Finisher & $1001-2500$ finishers \\
$5-\mathrm{O}$ & Breeder & $1001-2500$ sows \\
$6-\mathrm{O}$ & Breeder & $1001-2500$ sows \\
$7-\mathrm{O}$ & Farrow-to-finish & $<750$ sows \\
$8-\mathrm{O}$ & Breeder & $750-1000$ sows \\
$9-\mathrm{O}$ & Breeder & $750-1000$ sows \\
\hline \hline
\end{tabular}

Development Board - Pork) or through contact with pig companies or pig vets linked to outdoor sites. These farms were contacted by e-mail and followed up by telephone to identify willing participants that were planning on moving site in the coming year and were outdoor breeder-finishers, outdoor breeders (preferably supplying a single finisher) or outdoor finishers only (preferably supplied by single source). Nine farms participated in the study and these consisted of five breeder farms, three finishers and one farrow-to-finish farm. Details of each farm and the sampled outdoor sites are provided in Table 1.

\section{Schedule for sampling visits}

Each farm was visited four times over a 12-month period, with all visits completed between June 2014 and December 2015. The farm visits covered the sampling of the outdoor pigs prior to any change of site and then three visits after movement to a new site 4 months apart, to evaluate the benefits. On outdoor breeding farms, the groups and numbers of sows remained relatively stable between the old and the new site and no additional monitoring was needed for oncoming stock, as gilt groups were included in the ongoing sampling before and after the move. However, if a recruited farm supplied an indoor finisher owned by the same company, then consent was sought to sample the progeny from the outdoor sows within 5 days of the visit to the breeding site. If the recruited farm was an outdoor finisher, then new pigs were being brought onto the site and leaving for slaughter at regular intervals and so the same cohort of animals could not be followed throughout the whole 12-month intervention. The sample visits for these farms were based around sampling before the move, after the move, directly after the 
Table 2. Farm management and structure information collected from questionnaires used on the nine outdoor pig farms (copies of the forms can be requested from the authors)

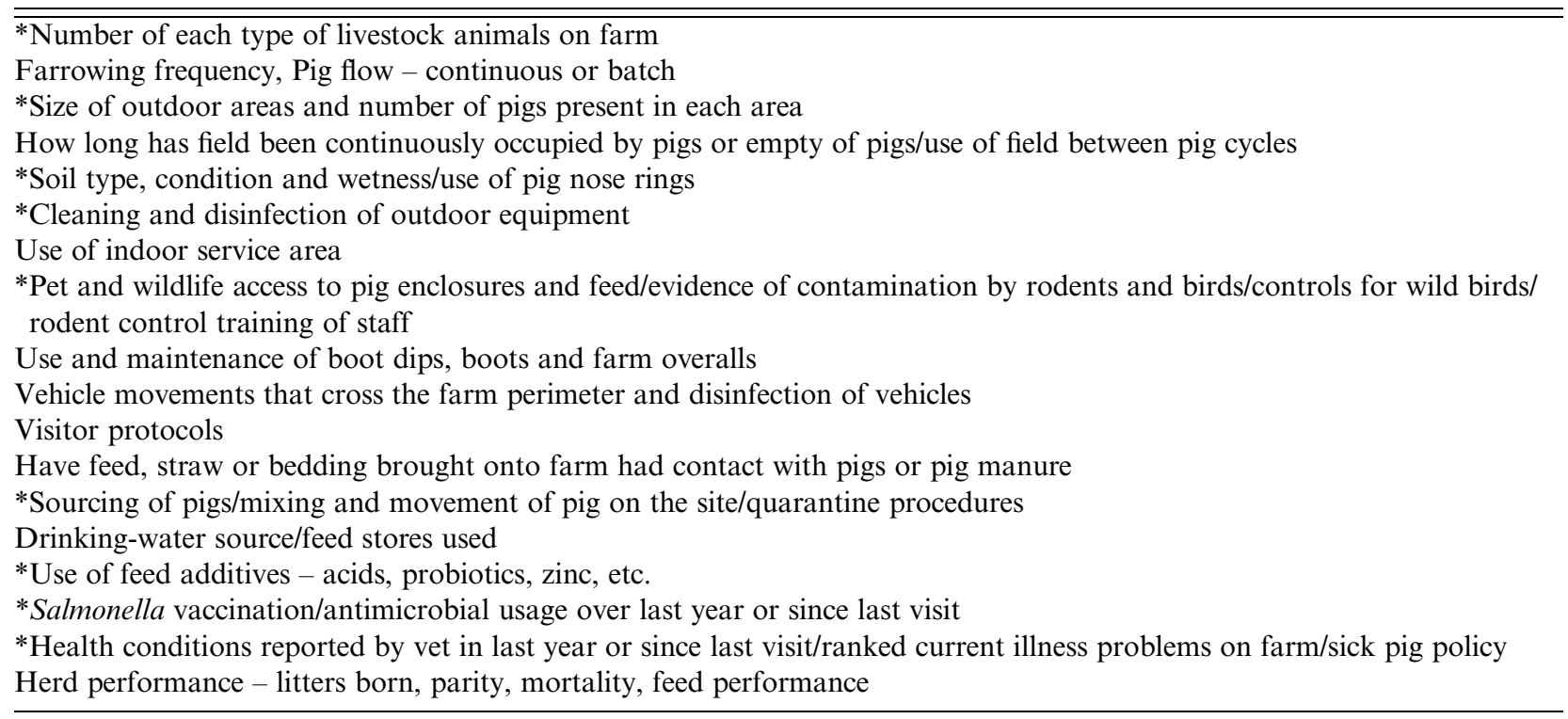

*Indicates information that was updated at subsequent farm visits.

introduction of the second group of finishers, and then a final visit after 12 months to test long-term effects of movement.

\section{Data collection}

At the initial visit, a thorough questionnaire was completed with the farmer to collect farm information on the original location and pig health and management (Table 2). At each subsequent visit, a short form was completed to detail the new site (at visit 2) and identify any changes to the farm management since the last visit, and other general observations that might have influenced the Salmonella results. At each sampling visit, a data collection form was completed to record information on the sampled groups of pigs (number present and type, health conditions present, feeder/drinker type, accommodation and bedding types) and a map was produced to identify the layout of the farm and show where samples were collected.

\section{Samples collected}

A combination of pooled and individual fresh faecal dropping samples were collected at each visit, with between 200 and 300 collected per visit using the following protocol: at least 60 pooled samples were collected from the farrowing sow paddocks, representing every field, with a maximum of 30 samples collected per separate field. For every three individually penned sows, a pooled sample was collected, made up of two faecal pinches per sow (6 pinches in total). If sows were grouped for farrowing then the sampling was increased to match the number of sows. Pooled faecal samples (c.40 g faeces each, comprising 10 pinches from separate fresh faecal droppings per pool) were collected from dry sow/service paddocks, up to a maximum of 60 per farm. Up to a maximum of 60 pooled gilt fresh faecal dropping samples were similarly collected from all gilt pens. At least 10 pooled samples were collected from maiden gilts and 10 from in-pig gilts. Individual faecal dropping samples were collected from the sows, with 60 collected from dry sows and 60 from lactating sows.

For outdoor weaner kennels or lairage, two swab samples (sterile gauze swab pre-moistened with phosphate-buffered saline (PBS)) were collected from the dunging area per kennel/pen, up to a maximum of 60 per visit and 60 individual weaner faecal samples were collected. If weaners had been moved to an indoor grower-finisher site where they could be identified and sampled (i.e. separate from animals coming from other sources) then up to 60 pen faeces swabs and 60 individual faeces were collected. Outdoor grower or finisher pigs were sampled using the same pooled and individual sampling methods as for the dry sows. At least 20 environmental (e.g. wallows, pooled water on tracks, feed troughs, water troughs, 
soil in empty paddocks, equipment), wildlife (wild bird and rodent faeces) or other livestock species faeces (for those kept in close proximity to the pigs) samples were collected from each farm visit, using PBS swabs for surfaces and manual collection for faeces, to represent a cross-section of environmental samples according to the layout of the farm.

\section{Sample testing}

All samples were tested for Salmonella using a method based on ISO6579 (Annex D; [18]) but with Rambach agar as the sole plating agar. Serotyping was carried out for isolates from all positive pooled samples and for those individual samples which were enumerated. Isolates of Salmonella typhimurium (ST), monophasic ST (MST) and Salmonella enteritidis (SE), selected to represent each farm visit and each pig stage, were phagetyped. Up to 40 positive individual faecal samples were enumerated, after cold storage $\left(4{ }^{\circ} \mathrm{C}\right)$ pending the initial result, using a dilution/enrichment method [19], to estimate the concentration of Salmonella present per gram of faeces. Two outcomes were generated to be used in the modelling analyses: whether a sample was Salmonella positive or not and whether a Salmonella serovar of major human health importance (ST, MST or SE) was detected.

\section{Data analysis}

Descriptive analyses were completed to describe the sample results at each visit and on each farm. A regression analysis was completed to model the difference in results at each visit, whilst accounting for $a$ priori variables of seasonality and sample type, and farm ID was added as a random effect to account for similarity of results collected from the same farm. Sinusoidal components (sine and cosine terms) for a quarterly cycle were included to account for seasonality [20]. To account for the difference in structure and management between the farms and the occurrence of changes to the farm between visits, a stepwise selection method was used to add variables from the questionnaire, and the form used for visits $2-4$, to the multivariable model. A screening stage was used to omit explanatory variables that had a $P$-value over 0.20 when added to the base model. After this, each variable was individually added to the model and the variable that was significant $(P<0.05)$ and improved the fit of the model (determined by Akaike Information Criteria) was added to the model. This approach was continued until no new variables entering the model were significant or improved the model fit. All analyses were completed in Stata 12 (Statacorp, College Station, Texas, USA).

\section{RESULTS}

A total of 8549 samples were collected from the farms, with $92 \%$ being pooled or individual faecal samples from pigs, and $8 \%$ being environmental or faeces samples from wildlife or cattle. Salmonella was most frequently detected in pooled pig faeces samples $(33 \cdot 2 \%)$ as well as from samples from run-off and pooled water $(47 \cdot 3 \%)$, rodent faeces $(40 \cdot 0 \%)$ and wild bird faeces $(37 \cdot 3 \%)$ (Table 3 ).

The results summarised for each set of visits indicated a reduction in the average Salmonella and ST/ MST/SE prevalence between visit 1 and 2 ; from $29 \cdot 6 \%$ to $16 \cdot 9 \%$ and $11 \cdot 0 \%$ to $6 \cdot 4 \%$, respectively (Table 4). The prevalence remained lower than at the baseline visit at both the third and the final visit, 12 months after the first visit.

The results were not consistent between the nine farms. Although most farms showed a substantial drop in pooled sample prevalence after the move to the new site, farm 8-O showed an increase in prevalence of Salmonella, which did not correspond with a change in serovars detected or outbreak of other diseases (Table 5). At the third visit ( 6 months after the move) most farms showed an increase in prevalence compared with visit 2 , but only one farm showed a small increase in prevalence in comparison to visit 1 (farm 1-O). Finally, a year after the move, six farms still showed a lower prevalence than at visit 1 . The variability of results was mirrored in the individual samples, with two farms showing an increase in prevalence after the move and three farms having a higher prevalence at visit 4 than at visit 1 .

From the pooled samples, up to 13 different serovars were detected at each farm visit (mean 5.5), with 37 different serovars detected in total. The most prevalent serovars were the two MST variants: $S$. 4,12:i:- (210 isolates) and $S .4,5,12: \mathrm{i}:-$ (200 isolates), followed by Salmonella derby (148), Salmonella rissen (124), Salmonella panama (115), Salmonella reading (112), S. typhimurium (111) and Salmonella bovismorbificans (110). Amongst the individual samples, 1-10 serovars were detected per visit (mean $3 \cdot 8$ ), with 25 different serovars detected in total. The most prevalent serovars were similar to those from the pooled 
Table 3. Salmonella detection by sample type from nine outdoor pig farms

\begin{tabular}{lllll}
\hline \hline $\begin{array}{l}\text { Pooled/individual } \\
\text { sample }\end{array}$ & Sample type & $\begin{array}{l}\text { Number of } \\
\text { samples }\end{array}$ & $\begin{array}{l}\text { Salmonella } \\
\text { positive }\end{array}$ & $\begin{array}{l}\text { Per cent } \\
\text { positive (\%) }\end{array}$ \\
\hline Individual & Pig faeces & 4321 & 650 & $15 \cdot 0$ \\
Pooled & Pig faeces & 3517 & 1168 & $33 \cdot 2$ \\
Pooled & Run off/pooled water & 239 & 113 & $47 \cdot 3$ \\
Pooled & Water troughs & 169 & 40 & $23 \cdot 7$ \\
Pooled & Feed troughs and ad-lib feed hoppers & 117 & 24 & $20 \cdot 5$ \\
Pooled & Wild bird faeces & 75 & 28 & $37 \cdot 3$ \\
Pooled & Pig handling equipment & 45 & 9 & $20 \cdot 0$ \\
Pooled & Farm tracks & 22 & 6 & $27 \cdot 3$ \\
Pooled & Vehicles & 19 & 5 & $26 \cdot 3$ \\
Pooled & Rodent faeces (rats or mice) & 15 & 6 & $40 \cdot 0$ \\
Pooled & Disinfected surfaces & 6 & 1 & $16 \cdot 7$ \\
Pooled & Other farm species (cattle) & 2 & 0 & $0 \cdot 0$ \\
Pooled & Waste handling & 2 & 0 & $0 \cdot 0$ \\
\hline \hline
\end{tabular}

Table 4. Summary of sample results from the visits to nine outdoor pigs herds

\begin{tabular}{lllllll}
\hline \hline & $\begin{array}{l}\text { Average number of } \\
\text { days since previous } \\
\text { Visit }\end{array}$ & $\begin{array}{l}\text { Number of } \\
\text { samples }\end{array}$ & $\begin{array}{l}\text { Number of Salmonella } \\
\text { positive }\end{array}$ & $\begin{array}{l}\text { Per cent } \\
\text { positive (\%) }\end{array}$ & $\begin{array}{l}\text { Number of } \\
\text { ST/MST/SE positive }\end{array}$ & $\begin{array}{l}\text { Per cent } \\
\text { positive (\%) }\end{array}$ \\
\hline Visit 1 & - & 2562 & 758 & $29 \cdot 6$ & 282 & $11 \cdot 0$ \\
Visit 2 & 114 & 1947 & 330 & $16 \cdot 9$ & 124 & $6 \cdot 4$ \\
Visit 3 & 149 & 2031 & 436 & $21 \cdot 5$ & 181 & $8 \cdot 9$ \\
Visit 4 & 119 & 2009 & 526 & $26 \cdot 2$ & 150 & $7 \cdot 5$ \\
\hline \hline
\end{tabular}

Table 5. Percentage of pooled and individual faecal samples positive for Salmonella at each visit to nine outdoor pig farms

\begin{tabular}{|c|c|c|c|c|c|c|c|c|}
\hline \multirow[b]{2}{*}{ Farm ID } & \multicolumn{4}{|c|}{ Pooled samples (per cent positive) } & \multicolumn{4}{|c|}{ Individual samples (per cent positive) } \\
\hline & Visit 1 & Visit 2 & Visit 3 & Visit 4 & Visit 1 & Visit 2 & Visit 3 & Visit 4 \\
\hline $1-\mathrm{O}$ & $26 \cdot 8$ & $4 \cdot 1$ & $29 \cdot 3$ & $28 \cdot 4$ & $12 \cdot 2$ & $2 \cdot 5$ & $26 \cdot 3$ & $11 \cdot 7$ \\
\hline $2-\mathrm{O}$ & $66 \cdot 0$ & $46 \cdot 7$ & $54 \cdot 2$ & $28 \cdot 3$ & $25 \cdot 0$ & $30 \cdot 0$ & $30 \cdot 4$ & $11 \cdot 7$ \\
\hline $3-\mathrm{O}$ & $83 \cdot 8$ & $2 \cdot 5$ & $63 \cdot 8$ & $28 \cdot 6$ & $33 \cdot 3$ & $1 \cdot 7$ & $38 \cdot 3$ & $11 \cdot 7$ \\
\hline $4-\mathrm{O}$ & $40 \cdot 4$ & $18 \cdot 8$ & $32 \cdot 5$ & $52 \cdot 4$ & $3 \cdot 3$ & $13 \cdot 3$ & $8 \cdot 3$ & $21 \cdot 7$ \\
\hline $5-\mathrm{O}$ & $45 \cdot 2$ & $23 \cdot 5$ & $18 \cdot 1$ & $31 \cdot 4$ & $22 \cdot 8$ & $1 \cdot 7$ & $4 \cdot 0$ & $14 \cdot 5$ \\
\hline $6-\mathrm{O}$ & $53 \cdot 8$ & $41 \cdot 4$ & $26 \cdot 4$ & $35 \cdot 0$ & $43 \cdot 5$ & $11 \cdot 1$ & $11 \cdot 2$ & $18 \cdot 4$ \\
\hline $7-\mathrm{O}$ & $17 \cdot 4$ & $12 \cdot 6$ & $8 \cdot 9$ & $3 \cdot 0$ & $4 \cdot 2$ & $1 \cdot 7$ & $3 \cdot 3$ & $1 \cdot 1$ \\
\hline $8-\mathrm{O}$ & $31 \cdot 2$ & $41 \cdot 7$ & $19 \cdot 7$ & $65 \cdot 8$ & $16 \cdot 2$ & $10 \cdot 9$ & $1 \cdot 7$ & $42 \cdot 0$ \\
\hline $9-\mathrm{O}$ & $48 \cdot 5$ & $32 \cdot 6$ & $47 \cdot 5$ & $41 \cdot 9$ & $22 \cdot 7$ & $10 \cdot 9$ & $28 \cdot 9$ & $26 \cdot 6$ \\
\hline
\end{tabular}

samples, with the two MST variants being most prevalent, followed by S. panama, S. derby, S. rissen and $S$. bovismorbificans. The number of serovars detected across samples at each visit varied, with an average of $6 \cdot 2$ separate serovars detected at the baseline visit, $4 \cdot 8$ at visit $2,5 \cdot 8$ at visit 3 and $6 \cdot 9$ at visit 4 .
From rodent samples, Salmonella London (two isolates), MST (1x 4,12:i:-), S. bovismorbificans (1), $S$. derby (1) and $S$. reading (1) were detected, whereas in wild bird faeces MST (six isolates of 4,12:i:- and four of 4,5,12:i:-), S. derby (8), S. rissen (4), ST (2), Salmonella anatum (1), Salmonella goldcoast (1), 
Table 6. Summary of the distribution of pig faeces samples within four categories of Salmonella concentration (cful g) from four farm visits

\begin{tabular}{|c|c|c|c|c|c|c|c|c|}
\hline \multirow[b]{2}{*}{ Visit } & \multicolumn{4}{|c|}{ Number of samples with each quantity } & \multicolumn{4}{|c|}{ Proportion of total } \\
\hline & $<1$ & $1-10$ & $10-10^{2}$ & $>10^{2}$ & $\%<1$ & $\% 1-10$ & $\% 10-10^{2}$ & $\%>10^{2}$ \\
\hline 1 & 134 & 37 & 13 & 12 & 68.4 & $18 \cdot 9$ & $6 \cdot 6$ & $6 \cdot 1$ \\
\hline 2 & 40 & 12 & 4 & 3 & 67.8 & $20 \cdot 3$ & $6 \cdot 8$ & $5 \cdot 1$ \\
\hline 3 & 93 & 27 & 12 & 5 & 67.9 & $19 \cdot 7$ & $8 \cdot 8$ & $3 \cdot 6$ \\
\hline 4 & 97 & 31 & 17 & 12 & $61 \cdot 8$ & $19 \cdot 7$ & $10 \cdot 8$ & $7 \cdot 6$ \\
\hline
\end{tabular}

S. London (1) and S. panama (1) were detected. Only five wild bird ST and MST isolates were phagetyped (3 DT193, 1 DT120 and 1 U288) and all but one (the DT120) matched phagetypes isolated from pigs on those farms, but DT120 strains are typically variants of DT193, which was found.

An average of 15 individual samples were selected for enumeration from each farm visit (range 1-40) to indicate the concentration of Salmonella in each sample. Estimates of numbers of salmonellae ranged between $<1$ and $10^{5}-10^{6} \mathrm{cfu} / \mathrm{g}$. Samples with the highest Salmonella level were only found at visit 1, and the number of samples with levels of $10^{4}-10^{5}$ increased from zero at visit 2 to 1 at visit 3 and 2 at visit 4. However, a summary of these results, categorised into four groups, indicated that the numbers did not differ widely between visits and the proportion of samples with levels over $10^{2} / \mathrm{g}$ were small $(\sim 5 \%)$ (Table 6$)$. The $\chi^{2}$ tests to investigate any significant difference between visits 1 and 2, 1 and 3, and 1 and 4 detected no statistically significant difference between the faecal Salmonella levels from these visits.

The results of the risk factor model indicate that the odds of a sample being positive was significantly lower at visits 2 and 3 when compared with the baseline visit, whereas the odds at the last visit was not significantly different (Table 7). The final model included three variables additional to the a priori variables for sample type and seasonality. These were: coughing in the sampled group which was a risk factor; Glasser's disease diagnosed in the herd since the last visit, which was protective; and the use of tent or kennel accommodation for the sampled group which was a risk when compared with arcs.

\section{DISCUSSION}

This longitudinal study of outdoor pig herds has provided evidence that movement of outdoor site has an overall beneficial effect on Salmonella carriage. The risk factor model, accounting for seasonality and different sample types, showed that the odds of a sample being positive was reduced by more than $50 \%$ after movement to the new site and by $25 \%$ at the third visit, both of which were statistically significant. The results also showed that the diversity of serovars detected after the site movement decreased and that the highest Salmonella level was only detected at the first visit, which supports this conclusion and suggests that the land was less contaminated before the pigs were moved to the new site but after a year the site was at a similar level of contamination to that previously. This finding provides important evidence for management changes that could help reduce Salmonella prevalence in outdoor herds. Additionally, Salmonella is a useful indicator bacterium, highlighting areas of poor control for other pathogens transmitted by faeces and so the improvements may also have impact on reducing the occurrence of other diseases [21]. However, it should be noted that moving site would incur a cost to the farmer and new land is not always available.

The reduction in prevalence was not shown for all studied farms, with one farm showing an increase in pooled faecal sample prevalence at visit 2 and one farm showing a pooled sample prevalence at visit 3 that was above visit 1 . The results for the individual faecal samples were more prone to fluctuations with greater numbers of farms showing prevalence increases at these stages, but smaller numbers of positive individual samples may have been associated with greater sample variability. For the two farms which showed increases in the pooled samples, no information collected by the questionnaire or discussion with the farmers could explain this difference. Some variation in the results may reflect seasonality, as farms were sampled at different times of the year and higher temperatures, potentially causing heat stress in the 
Table 7. Results from a mixed-effects model, determined by stepwise selection, assessing the effect of visit number on Salmonella prevalence on nine outdoor pig farms $\left(n=8548^{*}\right)$

\begin{tabular}{|c|c|c|c|c|c|c|c|c|}
\hline Variable & Level & $\begin{array}{l}\text { Number of } \\
\text { positive }\end{array}$ & $\begin{array}{l}\text { Number of } \\
\text { samples }\end{array}$ & $\begin{array}{l}\text { Per cent } \\
\text { positive }(\%)\end{array}$ & $\begin{array}{l}\text { Odds } \\
\text { ratio }\end{array}$ & $P$-value & $95 \% \mathrm{Cl}$ & \\
\hline \multirow[t]{4}{*}{ Visit } & 1 & 758 & 2562 & $29 \cdot 6$ & $1 \cdot 000$ & & & \\
\hline & 2 & 330 & 1947 & $16 \cdot 9$ & $0 \cdot 413$ & $<0.001$ & $0 \cdot 336$ & $0 \cdot 506$ \\
\hline & 3 & 436 & 2031 & $21 \cdot 5$ & 0.744 & $0 \cdot 025$ & $0 \cdot 574$ & $0 \cdot 964$ \\
\hline & 4 & 526 & 2009 & $26 \cdot 2$ & $1 \cdot 179$ & 0.083 & $0 \cdot 979$ & $1 \cdot 421$ \\
\hline \multirow[t]{2}{*}{ Sample type } & Individual & 650 & 4321 & $15 \cdot 0$ & $1 \cdot 000$ & & & \\
\hline & Pooled & 1400 & 4228 & $33 \cdot 1$ & $3 \cdot 051$ & $<0.001$ & $2 \cdot 709$ & $3 \cdot 436$ \\
\hline \multirow[t]{9}{*}{ Sampled area } & Gestation & 481 & 1165 & $41 \cdot 3$ & $1 \cdot 000$ & & & \\
\hline & Farrowing & 319 & 2301 & $13 \cdot 9$ & $0 \cdot 187$ & $<0.001$ & $0 \cdot 155$ & $0 \cdot 226$ \\
\hline & Weaners & 522 & 1480 & $35 \cdot 3$ & $0 \cdot 476$ & $<0.001$ & $0 \cdot 330$ & $0 \cdot 686$ \\
\hline & Growers & 132 & 575 & $23 \cdot 0$ & $0 \cdot 490$ & $0 \cdot 001$ & $0 \cdot 320$ & $0 \cdot 751$ \\
\hline & Finishers & 341 & 1677 & $20 \cdot 3$ & $0 \cdot 270$ & $<0 \cdot 001$ & $0 \cdot 200$ & $0 \cdot 364$ \\
\hline & Gilts & 91 & 245 & $37 \cdot 1$ & 0.649 & $0 \cdot 030$ & $0 \cdot 438$ & $0 \cdot 960$ \\
\hline & Maiden gilts & 3 & 9 & $33 \cdot 3$ & $0 \cdot 438$ & $0 \cdot 252$ & $0 \cdot 106$ & $1 \cdot 801$ \\
\hline & Dry sows & 144 & 1039 & $13 \cdot 9$ & $0 \cdot 309$ & $<0.001$ & $0 \cdot 236$ & $0 \cdot 405$ \\
\hline & Environmental & 17 & 58 & $29 \cdot 3$ & $1 \cdot 119$ & $0 \cdot 784$ & $0 \cdot 503$ & $2 \cdot 488$ \\
\hline \multirow[t]{2}{*}{ Sinusoidal quarterly cycle } & Sin & - & - & - & $0 \cdot 817$ & $0 \cdot 001$ & $0 \cdot 725$ & $0 \cdot 922$ \\
\hline & $\mathrm{Cos}$ & - & - & - & 0.975 & $0 \cdot 702$ & $0 \cdot 855$ & $1 \cdot 112$ \\
\hline \multirow[t]{3}{*}{ Coughing in sampled group } & No & 1909 & 8283 & $23 \cdot 0$ & $1 \cdot 000$ & & & \\
\hline & Yes & 141 & 265 & $53 \cdot 2$ & $4 \cdot 007$ & $<0 \cdot 001$ & $2 \cdot 779$ & $5 \cdot 777$ \\
\hline & N/A & 0 & 1 & $0 \cdot 0$ & $1 \cdot 000$ & & & \\
\hline \multirow{3}{*}{$\begin{array}{l}\text { Clinical Glasser's disease } \\
\text { present on farm }\end{array}$} & Yes & 937 & 3789 & $24 \cdot 7$ & $1 \cdot 000$ & & & \\
\hline & No & 925 & 3683 & $25 \cdot 1$ & $2 \cdot 043$ & $<0 \cdot 001$ & $1 \cdot 681$ & $2 \cdot 482$ \\
\hline & Missing & 188 & 1077 & $17 \cdot 5$ & $1 \cdot 287$ & $0 \cdot 129$ & $0 \cdot 929$ & $1 \cdot 783$ \\
\hline \multirow[t]{6}{*}{ Pig accommodation } & Arc & 921 & 5051 & $18 \cdot 2$ & $1 \cdot 000$ & & & \\
\hline & Hut & 214 & 947 & $22 \cdot 6$ & $1 \cdot 042$ & $0 \cdot 777$ & $0 \cdot 785$ & $1 \cdot 384$ \\
\hline & Kennel & 11 & 16 & $68 \cdot 8$ & $7 \cdot 732$ & $<0 \cdot 001$ & $2 \cdot 447$ & $24 \cdot 433$ \\
\hline & $\begin{array}{l}\text { Lairage } \\
\text { building }\end{array}$ & 30 & 94 & $31 \cdot 9$ & $1 \cdot 675$ & $0 \cdot 089$ & $0 \cdot 924$ & $3 \cdot 035$ \\
\hline & Tent & 810 & 2059 & $39 \cdot 3$ & $3 \cdot 816$ & $<0 \cdot 001$ & $2 \cdot 594$ & $5 \cdot 614$ \\
\hline & N/A or missing & 64 & 382 & $16 \cdot 8$ & 0.709 & $0 \cdot 138$ & $0 \cdot 451$ & $1 \cdot 116$ \\
\hline
\end{tabular}

CI, confidence interval; N/A, not applicable.

* One sample was omitted from the model as the answer to the coughing variable was not applicable and predicted success in the model perfectly.

pigs, has been linked to Salmonella shedding [22, 23]. Heavy rain before or during sampling visits may also have influenced the findings [24]. Although seasonality was accounted for in the risk factor model, it would not have reflected local weather conditions.

As Salmonella control is multifactorial, one simple intervention would not be expected to be consistently beneficial and other risk factors relating to management of pig herds and farm biosecurity, including pest control, must also be adequately implemented. Introduction of pigs from external sources and movement of staff and equipment between units are often poorly managed and could result in an increase in prevalence $[22,25,26]$. Interestingly, farm 2-O had a relatively high prevalence at each visit, and this farm was the only one that routinely introduced animals from multiple sources which were not part of the same company. This factor may have meant that the farm introduced different genotypes of Salmonella onto the farm during the study to which the population were naïve, which may have negated the effect of moving site for these serovars. However, the subset of 16 MST isolates that were phagetyped indicated the same phagetype was present at all four visits and importation of other pathogens that may have influenced susceptibility to Salmonella may also have occurred [13]. For the finisher farms, incoming groups of pigs after visit 2 were not sampled prior to movement to the new site, and it cannot be excluded that these pigs had a different baseline prevalence to the previous batch or that they introduced Salmonella to the site. 
The risk factor model identified only a small number of factors that were associated with Salmonella prevalence. As expected, the a priori variables showed that pooled samples were at greater risk of being positive than individuals and that there was a significant difference between samples collected from different pig stages. Samples from farrowing, weaner, grower, finisher, dry sow and gilt areas of the farm were all at lower risk compared with those from gestation areas. This may be related to greater movement and mixing of sows after weaning and during service procedures, together with higher stocking densities in more muddy paddocks and the use of floor feeding. Coughing detected in the sampled pigs was a risk factor and positive associations between Salmonella presence and pneumonia have been shown by previous studies [27, 28]. This may be due to the effect of one pathogen dampening the immune system and facilitating the infection of another, or may be due to Salmonella and respiratory conditions sharing similar risk factors, such as the use of straw-based housing and continuous flow production [14, 25, 29, 30]. However, the presence of Glasser's disease in the herd at a specific sampling visit was protective which is counterintuitive. This may have been due to random chance or it may have been a proxy for the effect of pig management factors used to control Glasser's disease, such as use of quarantine and improved cleaning and disinfection, that would also help protect against Salmonella. Pigs using kennels and tents were shown to be a greater risk than those using arcs which may be due to larger groups of younger pigs typically using this type of accommodation and the level of faecally contaminated liquid mud associated with such large groups. Additionally, solid structures such as arcs may be easier to clean between batches, whereas tents may remain contaminated and spread infection to new batches. The type of farm did not show a significant association with Salmonella, with finisher farms showing a similar pattern of change between the visits as the other farms. However, as only nine farms were included in the study, the power to detect differences at the farm level in the model may have been weak.

MST variants were the most common serovars detected, followed by other common pig serovars, such as $S$. derby. However, the number of serovars detected at each visit was high and contrasted to 26 indoor pig herds similarly sampled as part of a separate project (unpublished data). In these indoor herds an average of $2 \cdot 2$ serovars per farm (range 1-13) was detected in the pooled samples and 1.9 serovars per visit (range 1-5) from the individual samples. This suggests that outdoor herds have, on average, around double the number of serovars present. These findings, along with the high prevalence detected from samples from run-off and pooled water, and wild birds and rodents may highlight the greater risk of infection via environmental sources for outdoor pigs.

The results suggest that there is a likely benefit associated with annual movement of pigs compared with the typical 2-3 year cycle, and this may be cumulative if applied in successive years. However, there are practical and logistic difficulties as there is likely to be insufficient land available for pig farming for a significant increase in whole site movement and the labour cost for the move is high. It is likely however that better use could be made of more frequent resting and rotation of land used for paddock systems within a field site, since localised contamination of soil and surface water may be an important source of infection [31].

The semi-quantitative faecal culture results from this study suggest a high prevalence of low-level shedders of Salmonella, with occasional pigs being more highly colonised and acting as heavy shedders of the organism, thereby contaminating the environment of other pigs and driving cycles of infection [10]. Ingestion of soil and attraction of wild birds can be reduced by feeding gestational sows in troughs and other pigs using bird-proof ad-lib feeders, rather than floor feeding.

The study was limited by only visiting nine farms and although the structure of these farms was typical of outdoor farms, they may not represent all outdoor farm types. The findings on these farms may therefore reflect specific actions or management and may not be generalisable to the wider population. Additional fully controlled trials would be useful to attempt to reproduce these findings in other outdoor herds and to explore whether any benefits are seen for other pathogens. Future studies could also include long-term follow up of the farms at 16 and 24 months to see if any farms had maintained a lower prevalence for a sustained period. Additionally, further studies could test whether multiple yearly moves could result in a cumulative improvement in Salmonella prevalence and how crops and pigs can be rotated on land parcels to make more frequent movement cost-effective.

\section{ACKNOWLEDGEMENTS}

This work was supported by Defra project (project reference OZ0344). The authors would like to thank the 
farmers, their staff and their vets for their participation and assistance with this study. APHA staff are also thanked for their help with sampling these farms, processing the samples and data entering the information.

\section{DECLARATION OF INTEREST}

None.

\section{REFERENCES}

1. EFSA/ECDC. European Food Safety Authority and European Centre for Disease Prevention and Control, 2014. The European Union Summary Report on Trends and Sources of Zoonoses, Zoonotic Agents and Food-borne Outbreaks in 2012. EFSA Journal 2014; 12: 3547.

2. Hauser E, et al. Pork contaminated with Salmonella enterica Serovar 4,[5],12:I;-, an emerging health risk for humans. Applied and Environmental Microbiology 2010; 76: 4601-4610.

3. Anon. Report of the task force on zoonoses data collection on the analysis of the baseline survey on the prevalence of Salmonella in slaughter pigs, Part A. The EFSA Journal 2008; 135: 1-111.

4. Marier EA, et al. Abattoir based survey of Salmonella in finishing pigs in the United Kingdom 2006-2007. Preventive Veterinary Medicine 2014; 117: 542-553.

5. FAWC (Farm Animal Welfare Council). FAWC report on the welfare of pigs kept outdoors (https://www.gov. uk/government/publications/fawc-report-on-the-welfareof-pigs-kept-outdoors). Accessed 28 March 2017.

6. Houston S. Structure of the UK pig industry. The Pig Journal 2013; 69: 1-6.

7. Wingstrand A, Dahl J, Lo Fo Wong DMA. Salmonella-prevalences in Danish organic, free-range, conventional and breeding herds. In: Proceedings of the 3rd International Symposium on Epidemiology and Control of Salmonella in Pork, Washington, DC, USA, 1999, pp. 186-189.

8. van der Wolf PJ, et al. Salmonella seroprevalence at the population and herd level in pigs in the Netherlands. Veterinary Microbiology 2001; 80: 171-184.

9. EFSA. The European Union summary report on trends and sources of zoonoses, zoonotic agents and foodborne outbreaks in 2009. EFSA Journal 2011; 9: 1-378.

10. Jensen AN, et al. Survival and transmission of Salmonella enterica serovar typhimurium in an outdoor organic pig farming environment. Applied and Environmental Microbiology 2006; 72: 1833-1842.

11. Meyer C, Beilage GE, Krieter J. Salmonella seroprevalence in different pig production systems. Tieraerztl Prax Ausg Grosstiere Nutztiere 2005; 33: 104-112.

12. Quality Meat Scotland. Wild Bird Populations - Control and Impact: Contribution to Salmonella and Feed Costs on Indoor and Outdoor Pig Units. QMS, Leaflet, 2010.

13. Beloeil PA, et al. Risk factors for Salmonella enterica subsp. enterica shedding by market-age pigs in French farrow-to-finish herds. Preventive Veterinary Medicine 2004; 63: 103-120.

14. Nollet N, et al. Risk factors for the herd-level bacteriologic prevalence of Salmonella in Belgian slaughter pigs. Preventive Veterinary Medicine 2004; 65: 63-75.

15. Hotes $\mathbf{S}$, et al. Risk factors for Salmonella infection in fattening pigs - an evaluation of blood and meat juice samples. Zoonoses Public Health 2010; 57: 30-38.

16. Gebreyes WA, et al. Seroprevalence of Trichinella, Toxoplasma, and Salmonella in antimicrobial-free and conventional swine production systems. Foodborne Pathogens and Disease 2008; 5: 199-203.

17. Zheng DM, Bonde M, Sørensen JT. Associations between the proportion of Salmonella seropositive slaughter pigs and the presence of herd level risk factors for introduction and transmission of Salmonella in 34 Danish organic, outdoor (non-organic) and indoor finishing-pig farms. Livestock Science 2007; 106: 189-199.

18. International Organization for Standardization. Annex D: detection of Salmonella spp. in animal faeces and in environmental samples from the primary production stage (https://www.iso.org/standard/42109.html). Last accessed 28 March 2017.

19. Wales A, et al. A longitudinal study of environmental Salmonella contamination in caged and free-range layer flocks. Avian Pathology 2007; 36: 187-197.

20. Chatfield C. The Analysis of Time Series: an Introduction, 6th edn. Boca Raton, Florida, USA: CRC Press, 2003.

21. Bonde M, Sørensen JT. Herd health management in organic pig production using a quality assurance system based on Hazard Analysis and Critical Control Points. NJAS-Wageningen Journal of Life Sciences 2004; 52: 133-143.

22. Funk JA, Davies PR, Gebreyes W. Risk factors associated with Salmonella enterica prevalence in three-site swine production systems in North Carolina, USA. Berliner Und Munchener Tierarztliche Wochenschrift 2001; 114: 335-338.

23. Hald T, Andersen JS. Trends and seasonal variations in the occurrence of Salmonella in pigs, pork and humans in Denmark, 1995-2000. Berliner Und Munchener Tierarztliche Wochenschrift 2001; 114: 346-349.

24. Früh B, et al. Organic Pig Production in Europe - Health Management in Common Organic Pig Farming. 2011, First edition Technical guide (http://orgprints.org/19166/).

25. Lo Fo Wong DMA, et al. Herd-level risk factors for subclinical Salmonella infection in European finishing-pig herds. Preventive Veterinary Medicine 2004; 62: 253-266.

26. Wales AD, et al. Longitudinal survey of the occurrence of Salmonella in pigs and the environment of nucleus breeder and multiplier pig herds in England. Veterinary Record 2009; 165: 648-657.

27. Fedorka-Cray PJ, Gray JT, Wray C. Salmonella infections in pigs. In: Wray C, ed. Salmonella in Domestic Animals. Wallingford, UK: CABI Publishing, 2000, pp. 191-208.

28. Smith RP, et al. Abattoir-based study investigating the association between gross pathological lesions and serological tests for Salmonella infection in pigs. Veterinary Record 2011; 168: 240. 
29. Scott K, et al. The welfare of finishing pigs in two contrasting housing systems: fully-slatted versus strawbedded accommodation. Livestock Science 2006; 103: 104-115.

30. Maes D, et al. Control of Mycoplasma hyopneumoniae infections in pigs. Veterinary Microbiology 2008; 126: 297-309.
31. Baggesen DL, Dahl J, Wingstrand A, Nielsen $\mathbf{B}$. Detection of Salmonella enterica in different materials from the environment of pig herds. In: Bech-Nielsen $\mathrm{S}$, Nielsen JP, eds. Proceedings of the Second International Symposium on Epidemiology and Control of Salmonella in Pork. Copenhagen, Denmark, 1997, pp. 173-175. 